\title{
Nuptial gift consumption influences female remating in a scorpionfly: male or female control of mating rate?
}

\section{Leif Engqvist}

Received: 16 January 2006/ Accepted: 24 April 2006/

Published online: 28 September 2006

(C) Springer Science+Business Media B.V. 2006

\begin{abstract}
In the scorpionfly Panorpa cognata, males provide females with saliva secretions as nuptial food gifts. Consequently, females derive material benefits and possibly also genetic benefits from multiple matings. Females therefore generally should have a high motivation to remate. Males, on the other hand, do not share this interest, which will generate a sexual conflict over remating interval, possibly leading to male adaptations that prevent females from remating with other males. In this study, I found that mated females were less prone to copulate than virgin females, despite female benefits of multiple matings. Further, I found that the remating interval was significantly longer if the first copulation was long compared to shorter matings. This effect does not entirely depend on copulation duration per se, but on the amount of saliva, that a female is consuming during copulation. These results suggest a mating-induced refractory period and can be interpreted as male manipulation of female remating behaviour mediated through substances in the nuptial gift. Alternatively, receiving large nuptial gifts may decrease the prospective direct fitness benefits from further copulations, and thus change optimal female remating rate. Furthermore, gift size has been shown to correlate with male nutritional condition, which may be an indicator of male genetic quality. Females may therefore benefit indirectly by not remating following copulations involving large saliva gifts. In this scenario, female remating interval would be an effect of cryptic female choice.
\end{abstract}

Keywords Cryptic female choice $\cdot$ Mecoptera $\cdot$ Nuptial food gifts ·

Panorpa $\cdot$ Postcopulatory sexual selection $\cdot$ Sexual conflict $\cdot$ Sperm competition

\footnotetext{
L. Engqvist $(\square)$

Department of Evolutionary Biology and Ecology, University of Bonn, An der Immenburg 1,

D-53121 Bonn, Germany

e-mail: lengqvist@evolution.uni-bonn.de
} 


\section{Introduction}

It has been increasingly acknowledged that the postcopulatory component of sexual selection is of uttermost importance in order to understand the diversity and function of male and female reproductive behaviour (Eberhard 1996; Simmons 2001; Arnqvist and Rowe 2005). When females mate with more than one male, male reproductive success will not only be affected by their access to receptive female mating partners, but also by the competitive ability of their sperm in the subsequent struggle for fertilisations (Lewis and Austad 1990; Dziuk 1996). Postcopulatory sexual selection will thus act on such male traits that for instance (a) increase the relative number of sperm that are transferred during copulation (e.g. Dickinson 1986; Tsubaki and Sokei 1988; Parker et al. 1990; Eady 1995; Sakaluk and Eggert 1996; Sauer et al. 1998), (b) increase the fertilisation probability of each own sperm compared to the sperm of other males (e.g. Dziuk 1996; Birkhead et al. 1999) or (c) influence females to fertilise their eggs preferentially with the male's own sperm over the sperm from other males (see Eberhard 1996). Studies of female remating behaviour is therefore of high interest, as this will ultimately influence many aspects of sperm competition and cryptic female choice (e.g. Parker 1970; Thornhill 1983; Eberhard and Cordero 1995; Eberhard 1996; Simmons 2001).

Another way for a male to increase his reproductive success is to obstruct females from mating with or receive sperm from further males in the first place. Such behaviour has been described for a large number of species, and there are several different ways by which this may be accomplished. Males may for instance simply guard the females for a certain time after the copulation in order to reduce the likelihood that the female will remate (Sillén-Tullberg 1981; Sakaluk 1991; Alcock 1994). Further, mating plugs may enable the male to ceil the female genital tract and thus prevent other males from mating (Alcock 1994; Baer et al. 2001; Polak et al. 2001). Female oviposition, receptivity or attractiveness for other males may also be affected by stimulus substances transferred in male ejaculates (Leopold 1976; Chen 1984; Eberhard and Cordero 1995; Eberhard 1996; Chapman et al. 1998; Miyatake et al. 1999; Andersson et al. 2000; 2004).

Studies on female remating behaviour in species where females receive nuptial gifts or other direct material benefits at mating are of particular evolutionary interest. In these cases, females will be selected to mate frequently to collect gifts or benefits donated by males. Thus a sexual conflict (cf. Parker 1979; Arnqvist and Rowe 2005) over female remating behaviour will be generated, as male adaptations will be favoured that enforce or extend female refractory period in order to avoid sperm competition (Parker and Simmons 1989; Simmons and Gwynne 1991; Stockley 1997). Chemicals transferred at mating that increase the refractory period of females have frequently been reported (see Leopold 1976; Chen 1984; Chapman et al. 1998). In their theoretical analysis on male and female interests concerning nuptial feeding in insects, Parker and Simmons (1989) therefore interpreted these substances as a means by which males could manipulate female reproduction. Correspondingly, a number of studies on insect species with nuptial gifts have found a correlation between the amount of seminal fluid transferred or nuptial food gift consumed on the refractory period of females (Oberhauser 1989; Wedell and Arak 1989; He and Tsubaki 1991; Simmons and Gwynne 1991; Wedell 1993; 
Wiklund and Kaitala 1995; Johnson et al. 1999; Takakura 2001; Sakaluk et al. 2006).

Male influences on female remating behaviour must not necessarily have a negative impact on female fitness, even in species where females generally do benefit directly from multiple mating. Instead, females can possibly also benefit from a restrictive remating behaviour, if previous males have been of superior quality. This form of cryptic female choice was proposed in the pioneering studies by Thornhill (1976; 1983) on nuptial-prey-donating hangingflies (Mecoptera, Bittacidae), which showed that females receiving small prey gifts at mating remated sooner than females receiving larger gifts. This behaviour may be beneficial for females receiving large gifts, despite them wasting mating opportunities, as prey gift size correlates with male body size (Thornhill 1983). In addition, the overall marginal net direct fitness gain may be a decreasing function of female mating frequency. Thus, theory predicts an optimum female mating rate at which the benefits of remating will be balanced by the direct mating costs (Arnqvist and Nilsson 2000; Härdling and Kaitala 2005). The benefits and costs of mating may depend on several factors, such as for instance female nutrition, presence of predators and the phenotype of previous mates. Females may therefore respond adaptively by modulating remating behaviour in response to these factors. (see Arnqvist and Nilsson 2000 and references therein).

Here, I investigate the impact of copulation duration and nuptial gift consumption on the female refractory period in the scorpionfly Panorpa cognata (Ramb.). In this species, females typically mate with multiple males (Engqvist and Sauer 2003b) and benefit in several ways from polyandry. First, female scorpionflies often receive nuptial food gifts in form of salivary secretions at mating (Mercier 1915; Byers and Thornhill 1983; Sauer et al. 1998; Engqvist and Sauer 2003b; Engqvist 2006), and as showed for $P$. cognata, females derive nutritional benefits that increase their fecundity by consuming these gifts (L. Engqvist, unpublished data). In addition, $P$. cognata females benefit due to an increased egg-hatching rate by mating with different males (Engqvist 2006), possibly by avoiding genetic incompatibility (for reviews see Tregenza and Wedell 2000; Zeh and Zeh 2003; Simmons 2005). Nevertheless, far from all mating opportunities are used by females (see e.g. Engqvist and Sauer 2002). Matings may of course incur unknown costs to females, or these costs are only manifested in their natural environment. However, based on the current facts about $P$. cognata, a female refractory period would not seem to be in females' interest, at least not following females' first mating, as the estimated benefit of mating twice is quite substantial (Engqvist 2006). In this study, I therefore studied female remating behaviour and first compared the mating propensity of virgin and mated females. Thus, do matings induce a refractory period in female $P$. cognata? Second, an additional experiment was performed in order to evaluate if this remating interval is affected by the copulation duration of the preceding mating. Finally, a third experiment was designated in which the duration of female saliva consumption was manipulated independently from copulation duration. This was done in order to examine if the amount of saliva consumed per se affect remating interval irrespective of the amount of sperm and seminal fluid transferred at copulation. 


\section{Materials and methods}

\section{Study species}

The reproductive behaviour of $P$. cognata is described in detail in Engqvist and Sauer (2003b). In short, males present females with a nuptial gift prior to mating. This salivary secretion is consumed by the female during mating and females terminate copulations as soon as the secretion is consumed. The consumption of saliva during mating influences female egg production (L. Engqvist, unpublished data). Female egg laying may be onset immediately after their first mating and continue during the entire life span. However, females usually mate with several males prior to oviposition. Females lay eggs in batches of ca. 20-60 eggs and there is usually an interval of several days between oviposition bouts. In laboratory, females may mate 20 times during their life time, and on average females mate with 5-10 different males depending on the accessibility of gift giving males (Engqvist and Sauer 2003b).

For all experiments I used $\mathrm{F}_{1}$ offspring of animals collected near Freiburg in $\mathrm{Br}$. in south-western Germany. Standard breeding protocols for scorpionflies described elsewhere (e.g. Sauer 1970; 1977; Thornhill and Sauer 1992; Engqvist and Sauer 2001) were used. After adult emergence, all individuals were held individually in small plastic tubes $(8 \times 3.5 \mathrm{~cm})$ containing moist filter paper and food (see below). Sexual maturation and probably male attractiveness in this species is known to partly depend on nutrient availability (Engqvist and Sauer 2003b). Thus to avoid that the results on female remating behaviour would be confounded by either large variation in male attractiveness between trials or female willingness to mate, all individuals were held on a high nutrient diet consisting of a segment piece of a mealworm (Tenebrio molitor) every third day (see also Engqvist and Sauer 2001; 2003a). Nevertheless, to be able to control for this potential source of variation, all females and males were weighed prior to the mating trials to the nearest $0.1 \mathrm{mg}$. Furthermore, P. cognata males emit pheromones in order to attract females (Thornhill 1979; Engqvist and Sauer 2003b). The pheromonal gland of male scorpionflies is positioned on the genitalic bulb, and males emit pheromones by everting the gland. Only males that obviously were doing so were used.

\section{Mating trials}

All mating trials were staged in transparent plastic boxes $(10 \times 10 \times 7 \mathrm{~cm})$ containing moist filter paper. In addition, as $P$. cognata preferably mate on the underside of leaves, nettle plants (Urtica dioica) were cut at each internode, and all mating boxes were provided with a minute vessel containing such a miniature nettle plant and water.

Like many scorpionflies, $P$. cognata is crepuscular and nocturnal in its mating activities (Thornhill 1981; Engqvist and Sauer 2003b). Females approach pheromone emitting ("calling") males almost exclusively during the last hours prior to nightfall (Engqvist and Sauer 2003b). However, after males have attracted a female, there is usually a long delay, ranging from a few minute or minutes to almost $7 \mathrm{~h}$ (Engqvist and Sauer 2002; 2003b), before the male initiate copulation by secreting a salivary mass. I therefore made the experiments under a reversed day/ night cycle (see e.g. Engqvist and Sauer 2003b), starting the trials approximately 
$5 \mathrm{~h}$ (at 08:00 AM local time) prior to the dark phase. Male calling activity usually stops abruptly when it gets dark and courtship is very rarely initiated after this time. I therefore interrupted mating trials $2 \mathrm{~h}$ after the beginning of the dark phase when all calling had ceased, unless females had approached a male at that time point. Thus, every experimental day females had $7 \mathrm{~h}$ to approach a male for courtship to begin, but mating could begin later. In all experiments, females were restricted from laying eggs between trials, as this may uncontrollably change female motivation to remate.

Experiment 1: Female mating status and likelihood of copulations

This experiment was carried out during two consecutive generations. Totally, I observed the outcome of mating trials involving 352 virgin females and 100 randomly selected mated females. The mating trials of mated females were performed on the first day following their first mating. The mean \pm SD copulation duration in mated females' first copulation was $203.8 \pm 70.7 \mathrm{~min}$.

\section{Experiment 2: Copulation duration and remating interval}

Females were randomly assigned to one of two treatments. Either the females were first mated with a randomly chosen male for exactly $120 \mathrm{~min}(N=49)$ at which time copulations were interrupted by gently touching the pairs, and the females were separated from both the male and the salivary mass. Thus, these females copulated and consumed saliva for exactly $120 \mathrm{~min}$. I chose $120 \mathrm{~min}$, because this is a short copulation. Still it lays well within the range of naturally occurring copulations (see e.g. Engqvist and Sauer 2001; 2003a, b). The other group females were allowed to mate with a randomly chosen male without interruption $(N=48)$. Three females that failed to mate for longer than 120 min were discarded from further analyses. The mean \pm SD copulation duration of the remaining females amounted to $221.6 \pm 62.7 \mathrm{~min}$, which thus also corresponds to mean feeding time. Subsequently individual remating trials were performed every day with both groups of non-virgin females either until the female mated or at least for 14 days. Thus, I measured remating interval as the number of days elapsed between the females' first copulation and the day of remating. Every day a new randomly chosen male was used for each female and all males were used only once.

\section{Experiment 3: Nuptial gift consumption and remating interval}

All $(N=32)$ females used in this experiment were first mated with a randomly chosen male from the stock. These copulations were interrupted after exactly $120 \mathrm{~min}$. Half $(N=16)$ of the females were then separated from the salivary mass and were thus not permitted to feed on it for more than $120 \mathrm{~min}$. The other half $(N=16)$ were also separated from the salivary mass but were instantly offered a new fresh secretion produced by males in different matings trials that were staged with animals that were not else used in this experiment. Thus, these females also copulated for $120 \mathrm{~min}$ but were allowed to feed on secretions for much longer. It is difficult to accurately determine feeding time, as it would be necessary to observe the exact movements of the mouth parts (in darkness). However, all females finished their second salivary 
mass. Thus the average amount of saliva consumed by the females in this treatment roughly corresponds to the amount received prior to a copulation of $340 \mathrm{~min}$ (120 $\mathrm{min}+$ average copulation duration). This represents a very long copulation but is still well in the range of naturally occurring copulations (see e.g. Engqvist and Sauer 2001; 2003a, b). Subsequently individual remating trials were performed like the previous experiment. However, these trials were only performed for 6 days at least, as the previous experiment established that only ca. $10 \%$ of the females remate later than that. Here as well, I measured remating interval as the number of days elapsed between the females' first copulation and the day of remating.

\section{Statistical analysis}

I used log-likelihood ratios ( $G$-test) in order to analyse the effect of female mating status on the probability of copulations in standardised mating trials. However, in the last both experiments, remating interval was measured. As not all females remated, it was not possible to determine the remating interval for all females. To simply discard these observations from the further analysis would not be appropriate as they probably reflect a particularly long remating interval and may not be randomly distributed between experimental treatments. I therefore performed a survival analysis (also known as failure time- or time to event analysis), which enabled me to enter these data as censored observations (see Fox 2001; Therneau and Grambsch 2004). In these cases, the number of days that mating trials were performed without female remating was used instead of remating interval as the time measurement. All analyses were performed with R 2.1.0 (Ihaka and Gentleman 1996).

\section{Results}

Female mating status and likelihood of copulations

In the first generation I tested 156 virgin and 57 already mated females, whereas in the second generation I tested 196 virgin and 43 already mated females. There was no difference between generations neither in the proportion virgin females that mated in the mating trial (first generation: 72/156, second generation: 100/196, $G$-test: $\chi^{2}=0.82$, df $\left.=1, P=0.36\right)$, nor in the proportion mated females that mated in the mating trial (first generation: 20/57, second generation: 13/43, $G$-test: $\chi^{2}=0.26$, df $\left.=1, P=0.61\right)$. I therefore pooled the data from both generations. Virgin females were significantly more likely to mate in the trials than mated females (virgin females: $172 / 352=0.489$, mated females: $33 / 100=0.330, G$-test: $\chi^{2}=8.07$, df $=1, P=0.006)$.

\section{Copulation duration and remating interval}

Females, whose first copulation was interrupted at 120 min remated significantly earlier than females, which copulated for longer (Cox proportional hazards: female treatment $\beta=-0.49 \pm 0.22, z=-2.27, P=0.023$; Fig. 1$)$. Female weight was entered as a covariate in this analysis but failed significance (female weight $\beta=-0.019 \pm 0.013, z=-1.43, P=0.15)$. 


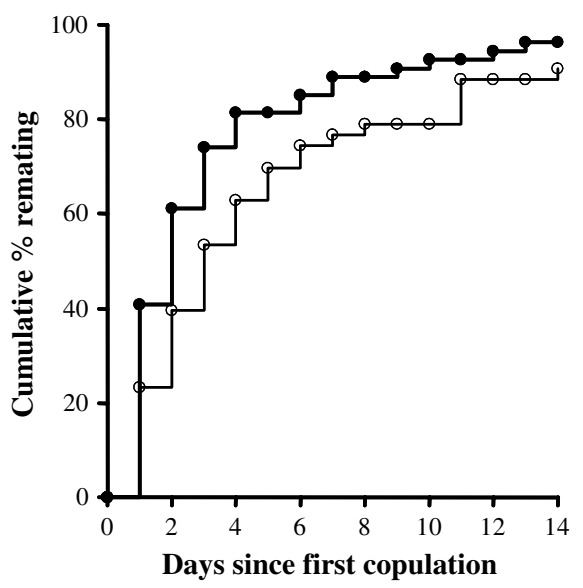

Fig. 1 Survival distribution for female remating dependent on the copulation duration of the previous mating (filled circles: copulation durations equal $120 \mathrm{~min}$, open circles: copulation durations longer than $120 \mathrm{~min}$ )

Nuptial gift consumption and remating interval

The survival analysis demonstrated that females that were restricted from feeding on the salivary secretions for more than 120 min remated significantly earlier than females that copulated equally long but were allowed to feed on surplus saliva, when controlling for female weight (Cox proportional hazards: female treatment $\beta=-1.02 \pm 0.449, z=-2.26, P=0.024$, Fig. 2 ). The difference in remating propensity between female treatments was apparent on the first day following mating (restricted vs. permitted: $9 / 16$ vs. $3 / 16 ; G$-test $\chi^{2}=4.97, \mathrm{df}=1, P=0.026$ ), but was still significant comparing the proportion females that had remated at the end of the experiment (restricted vs. permitted: $14 / 16$ vs. $8 / 16$; $G$-test $\chi^{2}=5.51, \mathrm{df}=1, P=0.019$ ). In addition, the survival analysis also showed that females that had a larger body mass

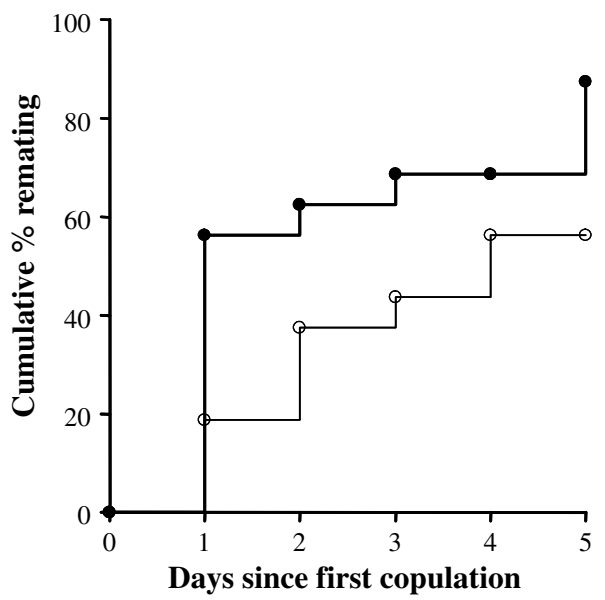

Fig. 2 Survival distribution for female remating dependent on the amount of salivary mass consumed in the previous mating (filled circles: salivary mass consumed for $120 \mathrm{~min}$, open circles: salivary mass consumed for longer than $120 \mathrm{~min}$ ). All copulations lasted for exactly $120 \mathrm{~min}$ 
remated significantly later than females that weighed less (Cox proportional hazards: female weight $\beta=-0.068 \pm 0.034, z=-1.97, P=0.049)$. When combining the effect of female body weight on remating propensity from the two experiments using the Ztransform test (see Whitlock 2005), I found that overall female weight significantly influenced female remating propensity $(z=2.40 ; P=0.016)$.

\section{Discussion}

This study has demonstrated that female $P$. cognata enter a refractory period, with reduced receptivity following mating. The duration of the female remating interval was influenced by copulation duration (Fig. 1) and the effect was mediated by the amount of saliva females were allowed to feed on during copulation (Fig. 2). Thus, large gifts size is a trait positively affected by the post copulatory component of sexual selection. Males will benefit by producing large salivary masses, as the risk and intensity of sperm competition will be reduced due to an increased female refractory period. Previous studies have shown that males must present a nuptial gift in order to achieve a copulation (Engqvist and Sauer 2003b): Furthermore, the production of larger nuptial gifts lead to copulations of longer duration (Engqvist and Sauer 2001), and thus ultimately increase sperm transfer (Engqvist and Sauer 2003a). Hence, the present finding adds a new aspect of a mating effort function (according to definition in Simmons and Parker 1989; see also Wedell 1993) of the male saliva secretions in this species.

This study complements other studies of nuptial gift giving insect species demonstrating that the size of the gift influences female receptivity and remating behaviour (Oberhauser 1989; Wedell and Arak 1989; He and Tsubaki 1991; Simmons and Gwynne 1991; Wedell 1993; Wiklund and Kaitala 1995; Johnson et al. 1999; Takakura 2001). In many butterflies and moths (Lepidoptera) the female remating interval correlates with the size of the spermatophore received at mating (e.g. Oberhauser 1989; He and Tsubaki 1991; Wiklund and Kaitala 1995). This effect of spermatophore size on female behaviour may be triggered by mechanical stimulation [i.e. stretch reception in the bursa copulatrix (Sugawara 1979)], the number of sperm stored by females at mating (e.g. Cook and Gage 1995; Cook and Wedell 1999), or possibly the amount of seminal fluids received by females (reviewed in Wedell 2005). Similarly, a few studies of crickets and bushcrickets (Orthoptera, Ensifera) have experimentally demonstrated that the duration of nuptial feeding, and hence gift size, influences female remating interval (Wedell and Arak 1989; Simmons and Gwynne 1991; Johnson et al. 1999; Sakaluk et al. 2006), whereas some studies found no effect of nuptial feeding on female remating behaviour (Brown 1997; Fleischman and Sakaluk 2004). Finally, females of the hangingfly Harpobittacus nigriceps (Mecoptera, Bittacidae) remate later after receiving large nuptial prey gifts (Thornhill 1983). In all these studies, the amount of nuptial gift consumed by females correlated with the ejaculate size received (but see Sakaluk et al. 2006) so that the influence on remating is likely to be mediated by the size of the ejaculate or any component of it (i.e. sperm, seminal fluid) (see. e.g. Wedell and Arak 1989). In contrast, the present study of scorpionflies demonstrated an effect of the amount saliva consumed independent of copulation duration and hence ejaculate size (cf. Engqvist and Sauer 2003a). In addition, mated females that were prevented to 
consume the gift in experiment 2 and 3 were more or less equally likely to remate on the first day following mating as virgin females were in experiment 1 (ca. 50\%, cf. Figs. 1 and 2). Thus, the effect on female refractory period demonstrated in the present study must, at least partly, be caused by the consumption of the salivary mass itself. Of course this does not exclude that the ejaculate or any of its components have an additional effect on female remating behaviour in this scorpionfly. The interpretation of the proximate and ultimate reasons for an increased female refractory period following consumption of a larger amount of saliva, however, may follow one of several possible evolutionary scenarios: either the saliva secretions may be an instrument for males to manipulate female mating frequency. Alternatively, females may either benefit directly or indirectly by adaptively modulating remating rate following matings with males able to secrete large amount of saliva.

Unless, there is very strong first male sperm precedence, selection will act on any male trait, that obstruct female remating with other males, as paternity will be lost in this case (Parker 1970; Simmons 2001). One very important and pervasive aspect of nuptial gifts is that they allow male direct access to the females' reproductive physiology (Vahed 1998; Weddle and Sakaluk 2003; Sakaluk et al. 2006). Malederived substances which affect female receptivity are common in insects (see e.g. Chapman et al. 1998; Wedell 2005 for examples in Diptera and Lepidoptera). Thus, there is the possibility that, disguised in nuptial gifts, males may transfer substances, which regulate female remating behaviour (see also Leopold 1976; Chen 1984). Accordingly, in their meta-analysis of benefits of female multiple mating in insects, Arnqvist and Nilsson (2000) showed that females of many gift-giving species mate at a lower than optimal rate, rendering support to this view.

In the present study, the amount of saliva consumed by females influenced their remating propensity, indicating that male saliva may entail substances that influence future female reproductive behaviour. If female unreceptivity confines female reproductive interests, the scenario of sexually antagonistic coevolution (see also Holland and Price 1998; Parker and Partridge 1998) would predict females to evolve an increased ability to neutralise the deleterious effect of remating inhibition, possibly by means of an increased capacity to metabolise transferred substances (discussed in Arnqvist and Nilsson 2000; Wiklund et al. 2001; Sakaluk et al. 2006). Therefore, inhibitory effects of male substances should tend to be dose dependant, which in fact seems to be the general pattern in insects (Eberhard 1996) and is in accordance with the results of this study. Male evolutionary response would therefore be to exaggerate the amount of inhibitory substances in each saliva gift even more and so forth. A recent study on nuptial gift-giving crickets (Sakaluk et al. 2006) has given compelling evidence for this evolutionary scenario.

A sexual conflict regarding remating interval would not be operating if females actually gain from a refractory period. Females receiving large nutritious gifts may temporarily be satiated. Time and energy may therefore be spent entirely on for instance search for suitable oviposition sites. This form of cryptic female choice, from which females benefit directly, has been shown to operate in Harpobittacus nigriceps (Thornhill 1983). Refractory periods due to female satiation, however, are expected to be of relatively short duration. Direct satiation effects can therefore, at most, only partly explain the results of the present study, as increased copulation duration and saliva consumption affected female remating behaviour for several days (cf. Figs. 1 and 2). Nevertheless, the amount of saliva received in previous matings may affect the expected benefits from further matings and thus directly 
affect female remating propensity. If females have already received a large amount of saliva during previous matings, the benefit of receiving further nuptial gifts may not be as high as for females that only received small gifts. Accordingly, Härdling and Kaitala (2005) in their theoretical treatment demonstrated that females should respond with a decreased remating rate when the marginal fitness benefits of each mating is higher. In line with the argument that females adaptively adjust female mating rate, I found that females with small body masses remated sooner than heavier females. It is a conceivable idea that the value of further matings and nuptial gift consumption may be a decreasing function of female body condition (see also Simmons and Gwynne 1991; Brown 1997)

In addition, if the saliva amount offered by males correlate positively with male genetic quality, female unreceptivity may be indirectly beneficial, as it will increase the genetic quality of female offspring (Jennions and Petrie 2000). In P. cognata, males in good condition are able to copulate longer than males in poor condition (cf. Engqvist and Sauer 2003a), as there is a strong relation between male condition and male ability to secrete saliva (Engqvist and Sauer 2001). In scorpionflies, which are highly food resource limited (e.g. Thornhill 1980; Bockwinkel and Sauer 1994; Sauer et al. 1998), there are good reasons to believe that individual condition may reflect quality, both in terms of food search ability and in aggressive interactions over food items (Sauer et al. 1998). However, both theoretical analyses and meta-analyses of empirical data have revealed that indirect effects are expected to be small compared to direct effects on offspring fitness (Kirkpatrick 1996; Kirkpatrick and Barton 1997; Alatalo et al. 1998; Møller and Jennions 2001). Nevertheless, there is at least the potential that females of $P$. cognata may benefit from this form of cryptic female choice. Proximately, females may perceive the size of the salivary mass, and thus male condition, by mechanical receptors in the gut that signal meal size (see Bernays and Simpson 1982) as suggested by Simmons and Gwynne (1991) as explanation in a similar study of a bushcricket.

It has been shown that males of many species may detect and adjust their behaviour according to the mating status of females (e.g. Simmons et al. 2003; Siva-Jothy and Stutt 2003). If males, for instance discriminate against females which have copulated for longer and received a larger amount of sperm, female refractory periods may be mistaken for what is really male choice. Studies of this kind therefore have the potential to be partly influenced by male discriminatory behaviour. However, this effect can be ruled out in the present study of $P$. cognata, as females actively approach "calling" males and courtship almost invariably ends with either copulations or female departure; males almost never depart (see Engqvist and Sauer 2002; 2003b).

In conclusion, this study has demonstrated an effect of salivary mass consumption on female refractory period in a scorpionfly. Thus, males producing a large salivary mass at mating have a reproductive advantage as they will experience a reduced risk and intensity of sperm competition. Future studies of the reproductive physiology may be able to determine if this is achieved in conflict or in accordance with the reproductive interests of females and thus be able to discriminate between the two conflicting hypotheses sexual conflict and female adaptive adjustment of mating rate.

Acknowledgements I thank Joachim Frommen, Roger Härdling and two anonymous reviewers for helpful comments on the manuscript and Kim Schmidt, Nicole Schmidt and Monika Kräling for help with laboratory work. This study was supported by the Deutsche Forschungsgemeinschaft [EN 469/1-1]. 


\section{References}

Alatalo RV, Kotiaho J, Mappes J, Parri S (1998) Mate choice for offspring performance: major benefits or minor costs? Proc R Soc Lond B 265:2297-2301

Alcock J (1994) Postinsemination associations between males and females in insects: the mateguarding hypothesis. Annu Rev Entomol 39:1-21

Andersson J, Borg-Karlson AK, Wiklund C (2000) Sexual cooperation and conflict in butterflies: a male-transferred anti-aphrodisiac reduces harassment of recently mated females. Proc R Soc Lond B 267:1271-1275

Andersson J, Borg-Karlson AK, Wiklund C (2004) Sexual conflict and anti-aphrodisiac titre in a polyandrous butterfly: male ejaculate tailoring and absence of female control. Proc R Soc Lond B 271:1765-1770

Arnqvist G, Nilsson T (2000) The evolution of polyandry: multiple mating and female fitness in insects. Anim Behav 60:145-164

Arnqvist G, Rowe L (2005) Sexual conflict. Princeton University Press, Princeton

Baer B, Morgan ED, Schmid-Hempel P (2001) A nonspecific fatty acid within the bumblebee mating plug prevents females from remating. Proc Natl Acad Sci USA 98:3926-3928

Bernays EA, Simpson SJ (1982) The control of food intake. Adv Insect Physiol 16:59-118

Birkhead TR, Martinez JG, Burke T, Froman DP (1999) Sperm mobility determines the outcome of sperm competition in the domestic fowl. Proc R Soc Lond B 266:1759-1764

Bockwinkel G, Sauer KP (1994) Resource dependence of male mating tactics in the scorpionfly, Panorpa vulgaris (Mecoptera, Panorpidae). Anim Behav 47:203-209

Brown WD (1997) Female remating and the intensity of female choice in black-horned tree crickets, Oecanthus nigricornis. Behav Ecol 8:66-74

Byers GW, Thornhill R (1983) Biology of the Mecoptera. Annu Rev Entomol 28:203-228

Chapman T, Miyatake T, Smith HK, Partridge L (1998) Interactions of mating, egg production and death rates in females of the Mediterranean fruit fly, Ceratitis capitata. Proc R Soc Lond B 265:1879-1894

Chen PS (1984) The functional-morphology and biochemistry of insect male accessory-glands and their secretions. Annu Rev Entomol 29:233-255

Cook PA, Gage MJG (1995) Effects of risks of sperm competition on the numbers of eupyrene and apyrene sperm ejaculated by the moth Plodia interpunctella (Lepidoptera, Pyralidae). Behav Ecol Sociobiol 36:261-268

Cook PA, Wedell N (1999) Non-fertile sperm delay female remating. Nature 397:486

Dickinson JL (1986) Prolonged mating in the milkweed beetle Labidomera clivicollis clivicollis (Cleoptera: Chrysomelidae): a test of the "sperm loading" hypothesis. Behav Ecol Sociobiol $18: 331-338$

Dziuk PJ (1996) Factors that influence the proportion of offspring sired by a male following heterospermic insemination. Anim Reprod Sci 43:65-88

Eady PE (1995) Why do male Callosobruchus maculatus beetles inseminate so many sperm? Behav Ecol Sociobiol 36:25-32

Eberhard WG (1996) Female control: sexual selection by cryptic female choice. Princeton University Press, Princeton, NJ

Eberhard WG, Cordero C (1995) Sexual selection by cryptic female choice on male seminal products-a new bridge between sexual selection and reproductive physiology. Trends Ecol Evol 10:493-496

Engqvist L (2006) Females benefit from mating with different males in the scorpionfly Panorpa cognata. Behav Ecol 17:435-440

Engqvist L, Sauer KP (2001) Strategic male mating effort and cryptic male choice in a scorpionfly. Proc R Soc Lond B 268:729-735

Engqvist L, Sauer KP (2002) Amorous scorpionflies: causes and consequences of the long pairing prelude of Panorpa cognata. Anim Behav 63:667-675

Engqvist L, Sauer KP (2003a) Determinants of sperm transfer in the scorpionfly Panorpa cognata: male variation, female condition and copulation duration. J Evol Biol 16:1196-1204

Engqvist L, Sauer KP (2003b) Influence of nutrition on courtship and mating behaviour in the scorpionfly Panorpa cognata. Ethology 109:911-928

Fleischman RR, Sakaluk SK (2004) Sexual conflict over remating in house crickets: no evidence of an anti-aphrodisiac in males' ejaculates. Behaviour 141:633-646 
Fox GA (2001) Failure-time analysis: emergence, flowering, survivorship, and other waiting times. In: Scheiner SM, Gurevitch J (eds) Design and analysis of ecological experiments. Oxford University Press, Oxford, pp 253-289

Härdling R, Kaitala A (2005) The evolution of repeated mating under sexual conflict. J Evol Biol 18:106-115

He Y, Tsubaki Y (1991) Effects of spermatophore size on female re-mating in the armyworm, Pseudoletia separata with reference to larval crowding. J Ethol 9:47-50

Holland B, Price WR (1998) Chase-away sexual selection: antagonistic seduction versus resistance. Evolution 52:1-7

Ihaka R, Gentleman R (1996) R: a language for data analysis and graphics. J Comput Graph Statist 5:299-314

Jennions MD, Petrie M (2000) Why do females mate multiply? A review of the genetic benefits. Biol Rev 75:21-64

Johnson JC, Ivy TM, Sakaluk SK (1999) Female remating propensity contingent on sexual cannibalism in sagebrush crickets, Cyphoderris strepitans: a mechanism of cryptic female choice. Behav Ecol 10:227-233

Kirkpatrick M (1996) Good genes and direct selection in evolution of mating preferences. Evolution 50:2125-2140

Kirkpatrick M, Barton NH (1997) The strength of indirect selection on female mating preferences. Proc Natl Acad Sci USA 94:1282-1286

Leopold RA (1976) The role of male accessory glands in insect reproduction. Annu Rev Entomol 21:199-221

Lewis SM, Austad SN (1990) Sources of intraspecific variation in sperm precedence in red flour beetles. Am Nat 135:351-359

Mercier L (1915) Caractère sexuel secondaire chez les Panorpes: le rôle des glandes salivaires des males. Arch Zool Exp 55:1-5

Miyatake T, Chapman T, Partridge L (1999) Mating-induced inhibition of remating in female Mediterranean fruit flies Ceratitis capitata. J Insect Physiol 45:1021-1028

Møller AP, Jennions MD (2001) How important are direct fitness benefits of sexual selection? Naturwissenschaften 88:401-415

Oberhauser KS (1989) Effects of spermatophores on male and female monarch butterfly reproductive success. Behav Ecol Sociobiol 25:237-246

Parker GA (1970) Sperm competition and its evolutionary consequences in the insects. Biol Rev 45:525-567

Parker GA (1979) Sexual selection and sexual conflict. In: Blum MS, Blum NA (eds) Sperm competition and the evolution of animal mating systems. Academic Press, New York, pp 1-60

Parker GA, Simmons LW (1989) Nuptial feeding in insects: theoretical models of male and female interests. Ethology 82:3-26

Parker GA, Partridge L (1998) Sexual conflict and speciation. Philos Trans R Soc Lond B 353:261-274

Parker GA, Simmons LW, Kirk H (1990) Analysing sperm competition data: simple models for predicting mechanisms. Behav Ecol Sociobiol 27:55-65

Polak M, Wolf LL, Starmer WT, Barker JSF (2001) Function of the mating plug in Drosophila hibisci Bock. Behav Ecol Sociobiol 49:196-205

Sakaluk SK (1991) Post-copulatory mate guarding in decorated crickets. Anim Behav 41:207-216

Sakaluk SK, Eggert A-K (1996) Female control of sperm transfer and intraspecific variation in sperm. Evolution 50:694-703

Sakaluk SK, Avery RL, Weddle CB (2006) Cryptic sexual conflict in gift-giving insects: chasing the chase-away. Am Nat 167:94-104

Sauer KP (1970) Zur Monotopbindung einheimischer Arten der Gattung Panorpa (Mecoptera) nach Untersuchungen im Freiland und im Laboratorium. Zool Jahrb Syst 97:201-284

Sauer KP (1977) The adaptive significance of genetic variability of photoperiodic response in Panorpa vulgaris. Zool Jahrb Syst 104:489-538

Sauer KP, Lubjuhn T, Sindern J, Kullmann H, Kurtz J, Epplen C, Epplen JT (1998) Mating system and sexual selection in the scorpionfly Panorpa vulgaris (Mecoptera: Panorpidae). Naturwissenschaften 85:219-228

Sillén-Tullberg B (1981) Prolonged copulation-a male post-copulatory strategy in a promiscuous species, Lygaeus equestris (Heteroptera, Lygaeidae). Behav Ecol Sociobiol 9:283-289

Simmons LW (2001) Sperm competition and its evolutionary consequences in the insects. Princeton University Press, Princeton, NJ 
Simmons LW (2005) The evolution of polyandry: sperm competition, sperm selection, and offspring viability. Ann Rev Ecol Evol Syst 36:125-146

Simmons LW, Parker GA (1989) Nuptial feeding in insects: mating effort versus paternal investment. Ethology 81:332-343

Simmons LW, Gwynne DT (1991) The refractory period of female katydids (Orthoptera: Tettigonidae): sexual conflict over the remating interval? Behav Ecol 2:276-282

Simmons LW, Alcock J, Reeder A (2003) The role of cuticular hydrocarbons in male attraction and repulsion by female Dawson's burrowing bee, Amegilla dawsoni. Anim Behav 66:677-685

Siva-Jothy MT, Stutt AD (2003) A matter of taste: direct detection of female mating status in the bedbug. Proc R Soc Lond B 270:649-652

Stockley P (1997) Sexual conflict resulting from adaptations to sperm competition. Trends Ecol Evol 12:154-159

Sugawara T (1979) Stretch reception in the bursa copulatrix of the butterfly, Pieris rapae crucivora, and its role in behavior. J Comp Physiol 130:191-199

Takakura K (2001) Courtship-role-reversal in the bean weevil, Bruchidius dorsalis (Coleoptera: Bruchidae): interplay between male-male competition and cryptic female choice. Appl Entomol Zoolog 36:311-316

Therneau TM, Grambsch PM (2004) Modeling survival data: extending the Cox model, 3rd edn. Springer, New York

Thornhill R (1976) Sexual selection and nuptial feeding behaviour in Bittacus apicalis (Insecta: Mecoptera). Am Nat 110:529-548

Thornhill R (1979) Male pair-formation pheromones in Panorpa scorpionflies (Mecoptera: Panorpidae). Environ Entomol 8:886-888

Thornhill R (1980) Competition and coexistence among Panorpa scorpionflies (Mecoptera: Panorpidae). Ecol Monogr 50:179-197

Thornhill R (1981) Panorpa (Mecoptera: Panorpidae) scorpionflies: systems for understanding resource-defense polygyny and alternative male reproductive efforts. Ann Rev Ecol Syst 12:355-386

Thornhill R (1983) Cryptic female choice and its implications in the scorpionfly Harpobittacus nigriceps. Am Nat 122:765-788

Thornhill R, Sauer KP (1992) Genetic sire effects on the fighting ability of sons and daughters and mating success of sons in a scorpionfly. Anim Behav 43:255-264

Tregenza T, Wedell N (2000) Genetic compatibility, mate choice and patterns of parentage: invited review. Mol Ecol 9:1013-1027

Tsubaki Y, Sokei Y (1988) Prolonged mating in the melon fly, Dacus cucurbitae (Diptera: Tephritidae): competition for fertilization by sperm-loading. Res Popul Ecol 30:343-352

Vahed K (1998) The function of nuptial feeding in insects: a review of empirical studies. Biol Rev 73:43-78

Weddle CB, Sakaluk SK (2003) Ingestion of male haemolymph and mating propensity of female sagebrush crickets: no evidence of a male-derived antiaphrodisiac. Anim Behav 65:83-88

Wedell N (1993) Spermatophore size in bushcrickets: comparative evidence for nuptial gifts as a sperm protection device. Evolution 47:1203-1212

Wedell N (2005) Female receptivity in butterflies and moths. J exp Biol 208:3433-3440

Wedell N, Arak A (1989) The wartbiter spermatophore and its effect on female reproductive output (Orthoptera: Tettigonidae, Decticus verrucivorus). Behav Ecol Sociobiol 24:117-125

Whitlock MC (2005) Combining probability from independent tests: the weighted Z-method is superior to Fisher's approach. J Evol Biol 18:1368-1373

Wiklund C, Kaitala A (1995) Sexual selection for large male size in a polyandrous butterfly: the effect of body size on male versus female reproductive success in Pieris napi. Behav Ecol 6:6-13

Wiklund C, Karlsson B, Leimar O (2001) Sexual conflict and cooperation in butterfly reproduction: a comparative study of polyandry and female fitness. Proc R Soc Lond B 268:1661-1667

Zeh JA, Zeh DW (2003) Toward a new sexual selection paradigm: polyandry, conflict and incompatibility. Ethology 109:929-950 